\title{
Sigma Phase in Superduplex Stainless Steel: Formation, Kinetics and Microstructural Path
}

\author{
Gláucio Soares da Fonseca ${ }^{a}$, Phelipe Matias de Oliveira $^{a}$, Marília Garcia Diniz $^{b}$, Dimitry $^{2}$
}

Valerievitch Bubnoff ${ }^{a}$, José Adilson de Castro ${ }^{a}$

\author{
${ }^{a}$ Federal Fluminense University - UFF, Av. dos Trabalhadores, 420, Vila Santa Cecilia, CEP: $27255-$ \\ 125, Volta Redonda, RJ, Brazil \\ ${ }^{b}$ Rio de Janeiro State University - UERJ, São Francisco Xavier, 524, Maracanã, Bloco A, CEP: 20550- \\ 013, Rio de Janeiro, RJ, Brazil
}

Received: June 8, 2016; Revised: October 24, 2016; Accepted: November 21, 2016

\begin{abstract}
The superduplex stainless steels (SDSS) are widely used in chemical, oil and gas industries, to pipelines and storage material facilities. In welding process or working in temperature elevated, secondary phases may appear in the form of precipitates, as the sigma phase $(\sigma)$ which is an intermetallic compound. This compound is harmful to the properties of steel, deteriorating its mechanical properties, such as decreasing corrosion resistance and toughness. In this paper it is analyzed the formation, kinetics and microstructural evolution of sigma phase in SDSS UNS S32750 after isothermal aging at $700^{\circ} \mathrm{C}, 750^{\circ} \mathrm{C}$ and $800^{\circ} \mathrm{C}$. In this work sigma phase kinetics is studied by JMAK theory and by two microstructural path descriptors, $S_{V}$, interfacial area per unit of volume between sigma phase and austenite, and $\langle\lambda\rangle$, mean chord length of sigma, both in function of the $V_{v}$, volumetric fraction of sigma, known in the literature as microstructural partial path (MP). The MP formulation is common in recrystallization studies, but so far has not been used in the sigma phase precipitation studies, being applied here for the first time. The results indicated that the sigma phase nucleates by site saturation with anisotropic linear impingement. This means that sigma phase nucleates on edges.
\end{abstract}

Keywords: Superduplex Stainless Steel, Sigma Phase, Kinetics, Microstructural Path, Impingement

\section{Introduction}

The superduplex stainless steels (SDSS) are widely used in chemical industry, oil and gas, in the pulp industry, applied to pipelines and storage material, and are often used in petrochemical industry, in oil extraction offshore platforms and storage tanks of chemicals. The SDSS have ferrite and austenitic phases balanced. Therefore, these steels have excellent properties due this combination, as corrosion resistance and good toughness ${ }^{1-3}$. However, for example, in welding process or working at elevated temperatures, secondary phases may appear as precipitate. These compounds are deleterious for steel properties. The principal precipitate that appears in this case is the sigma phase, although other precipitates such as chi phase or nitrites could be encountered. It is well known that the chi phase can be a precursor of the sigma phase which is also deleterious for the properties of SDSS. Therefore, it was considered that all these deleterious phases can be treated as sigma phase. This assumption was adopted in this work. Several works about this subject are found in literature ${ }^{1-10}$. These works based on sigma phase kinetics generally considered a theory by Johnson and Mehl ${ }^{11}$, Avrami $^{12-14}$ and Kolmogorov ${ }^{15}$, the JMAK theory or JMAK modified which may be written as:

$$
V_{V}=1-e^{\left(-k t^{n}\right)}
$$

Where $V_{V}$ - volume fraction of sigma, $\mathrm{t}$ is the time, $\mathrm{k}$ and $\mathrm{n}$ are constants, which depend of nucleation rate, growth rate and shape of precipitates, in this case. And $\mathrm{k}$ may be obtained by:

$$
k=k_{0} e^{\left(-\frac{Q}{R T}\right)}
$$

Where $\mathrm{Q}$ is this case, is activation energy for sigma phase formation and $\mathrm{R}$ is the universal gas constant $(8.31$ $\mathrm{J} / \mathrm{mol} . \mathrm{K}$ ). Summarizing, JMAK theory considers a random distribution of nuclei and a constant interface velocity. In this case, is necessary measure or modeling only volume fraction of sigma phase, $V_{V}$, in function of time. But, $V_{V}$, isn't enough for define nucleation mode. In this way, for studies of recrystallization, was developed microstructural path (MP) by Gokhale and DeHoff ${ }^{16}$, connect area per unit of volume, $S_{V}$, with $V_{V}$ and after extended by Vandermeer and coauthors ${ }^{17-20}$. MP which may be written $a^{21}$ :

$$
S_{V}=C_{0}\left(1-V_{V}\right)\left(-\ln \left(1-V_{V}\right)\right)^{q}
$$

Where $\mathrm{C}_{0}$ and $\mathrm{q}$ are constants that depend on the selected precise nucleation and growth models. Vandermeer concludes that $\mathrm{q}=0.667$, the impingement is uniform, in others words, random distribution. Thus, the nucleation is site-saturation. If there anisotropic impingement, $q=0.5$ for linear impingement or $\mathrm{q}=0$ for planar impingement. The other microstructural path descriptor $\langle\lambda\rangle$, the mean 
chord length, versus $V_{V}$, was derived by Vandermeer ${ }^{21}$ and obtained:

$$
<\lambda>=K_{\lambda}\left(V_{V}\right)^{1 / 3}\left(-\ln \left(1-V_{V}\right)\right)^{p}
$$

where $K_{2}$ and $p$ are constants that depend on nucleation mode and impingement. For example, $p=0$, uniform impingement - random nucleation, $\mathrm{p}=1 / 6$, linear impingement and $\mathrm{p}=2 / 3$, planar impingement. The MP formulation is common in recrystallization studies, but so far has not been used in the sigma phase precipitation studies, and will be applied here for the first time. In this work is considered the two MP descriptors, $S_{V}$ and $\langle\lambda\rangle$ in function of $V_{V}$. Therefore, in this work it will be studied the formation of sigma phase in SDSS in isothermal aging at $700^{\circ} \mathrm{C}, 750^{\circ} \mathrm{C}$ and $800^{\circ} \mathrm{C}$. Several authors ${ }^{2,6,8,22}$ found around of $850^{\circ} \mathrm{C}$ as the temperature of maximum sigma phase kinetics. We selected temperatures below of $850^{\circ} \mathrm{C}$. The reason for this is to analyze the beginning of the formation of sigma phase and understand the nucleation behavior. In this work, the samples were analyzed by optical microscope (OM), X-Ray Diffraction (XRD), and Microhardness Vickers (HV). These results help us to understand about nucleation and growth of sigma phase. Through OM, stereological measurements such as: $V_{V}, S_{V}$ and $<\lambda>$ were carried out. In this case $S_{V}$ means area interfacial per unit of volume between sigma phase and austenite. These results is useful to understand about sigma phase kinetics with the aid of JMAK and nucleation mode with the aid of MP formulation. This result is important, since is experimental evidence of the mechanism and can be used for modeling and design of theses SDSS knowing the nucleation mode and growth of sigma phase with impingement.

\section{Experimental Procedure}

The commercial SDSS UNS S32750 hot rolled was studied. The chemical composition is given in Table 1. Pieces were cut from as delivery plate with $10 \mathrm{~mm}$ of thickness to obtain samples with $20 \times 20 \times 10 \mathrm{~mm}$. Figure 1 shows a typical microstructure of the steel, as received.

Samples divided into three groups and each group was heat treated at different temperatures, $700^{\circ} \mathrm{C}, 750^{\circ} \mathrm{C}$ and $800^{\circ} \mathrm{C}$ and cooled in air. Samples were heat treated from $0.5 \mathrm{~h}$ to $50 \mathrm{~h}$. One sample was kept as a received (AR). After the heat treatments (HT) the specimens were ground with emery paper down to 2500 mesh. The samples were metallographic polished with $6 \mu \mathrm{m}, 3 \mu \mathrm{m}$ and $1 \mu \mathrm{m}$ diamond abrasive. After polishing, two different etchants were used. The first was Beraha reagent, composed of $20 \mathrm{~mL}$ hydrochloric acid $(\mathrm{HCl})$, $80 \mathrm{~mL}$ distilled water and $0.3 \mathrm{~g}$ potassium metabissulfide $\left(\mathrm{K}_{2} \mathrm{~S}_{2} \mathrm{O}_{5}\right)$ for $100 \mathrm{~mL}$ of aqueous solution. With this etching for 1 min can be distinguished: ferrite, austenite and sigma phase. To stereological quantification of sigma phase was used electrolytic etching with $10 \%$ potassium hydroxide $(\mathrm{KOH})$ aqueous solution. The etching was carried out at $0,3 \mathrm{~A}-1 \mathrm{~A}$ at $3 \mathrm{~V}$ and the etching time was about $1 \mathrm{~min}$.

\section{Stereological Measures, XRD and HV}

The samples were examined with Leitz Metallovert optical microscope. Micrographs were analyzed by public domain software image J. Particle characterization, volume fraction $\left(V_{V}\right)$, area interfacial per unit of volume between sigma phase and austenite, $S_{V}$, and mean chord length of sigma, $\langle\lambda\rangle$ was carried out by conventional quantitative metallography techniques ${ }^{21,23}$ :

$$
\begin{gathered}
V_{V}=P_{P} \\
S_{V}=2 P_{L} \\
<\lambda>=\frac{1}{P_{L}} V_{V}
\end{gathered}
$$

Where $P_{P}$ is average number of points falling on sigma phase divided by total number of points applied, $P_{L}$ is average number of intersections sigma phase/austenite with line per unit length of a random test $(L)$ line. In this work were used 10 lines per micrographs. $\mathrm{L}=0.16 \mathrm{~mm}$ for each isolated line.

$\mathrm{X}$-ray diffraction (XRD) equipment was used in this investigation. Consisted of a Shimadzu XRD 6000, Cu $\mathrm{K} \alpha$ tube. With this equipment, three austenite peaks, three ferrite peaks and four sigma phase peaks could be detected. In order to determine the hardness of the samples, the tests were performed in Shimadzu HMV Micro Vickers Hardness Tester. The experiments were carried out with load of 200 gram-Force by $20 \mathrm{~s}$.

\section{Results and Discussion}

Figure 1a shows AR micrograph. The ferrite $(\alpha)$ content is $47 \% \pm 3 \%$ and austenite $(\gamma)$ content is $53 \% \pm 4 \%$, balanced as expected. After HT sigma phase begins to nuclear and grow as shown in Figure 1b.

Increasing heat treatment time and temperature, the morphology of the phases obtained are presented in Figures $1 \mathrm{c}$ and $1 \mathrm{~d}$. The reaction should be eutectoid, $\alpha \rightarrow \sigma+\gamma_{2}$ as already found by other authors $4,5,7,8$.

Figures 1 a to $1 \mathrm{~d}$ shows that all ferrite was consumed. This process occurred at all temperatures, only faster at $800^{\circ} \mathrm{C}$. In fact, magnetic measured were carried out to confirm the existence of ferrite (using feritscope). It was confirmed that

Table 1: Chemical Composition of UNS S32750 (wt.(\%))

\begin{tabular}{lcccccccccc}
\hline $\mathrm{C}$ & $\mathrm{Si}$ & $\mathrm{Mn}$ & $\mathrm{P}$ & $\mathrm{S}$ & $\mathrm{Cr}$ & $\mathrm{Ni}$ & $\mathrm{Mo}$ & $\mathrm{N}$ & $\mathrm{Cu}$ \\
\hline 0.0205 & 0.328 & 0.85 & 0.0267 & 0.0009 & 24.89 & 6.82 & 3.72 & 0.278 & 0.156 \\
\hline
\end{tabular}




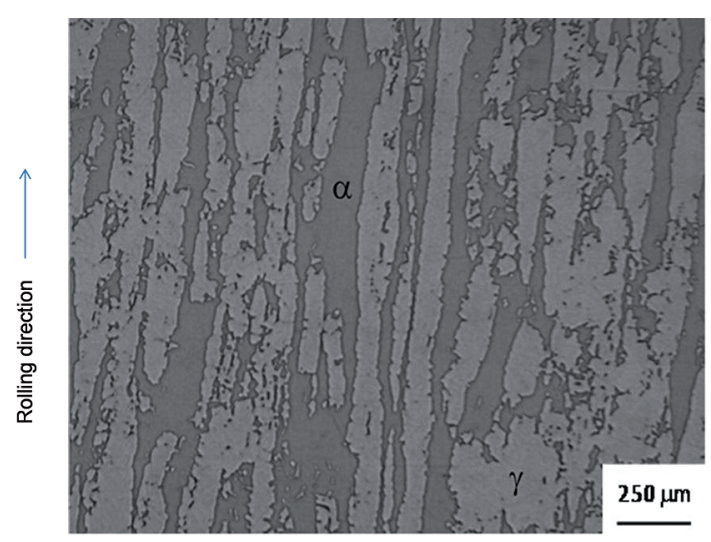

(a)

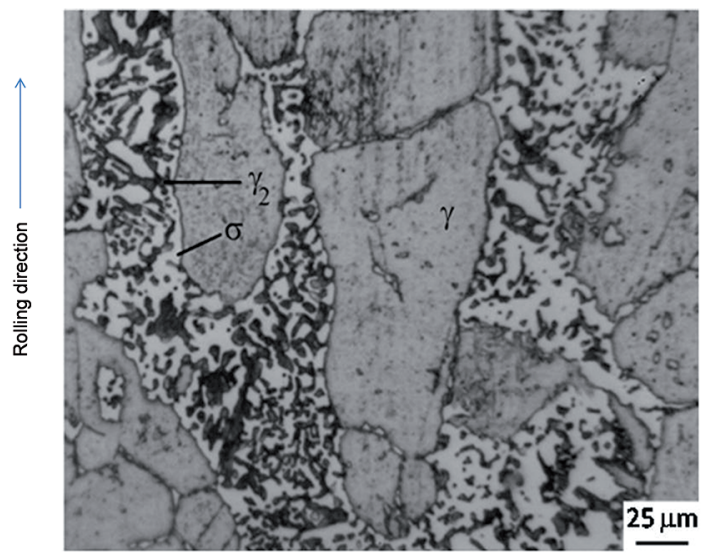

(c)

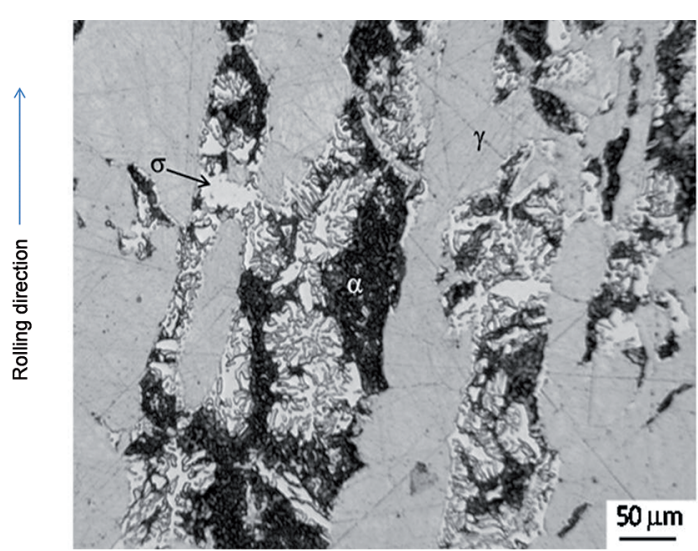

(b)

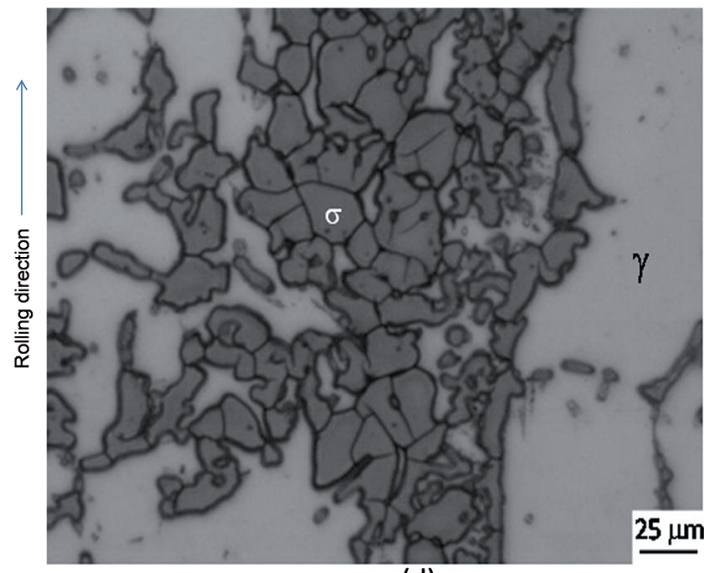

(d)

Figure 1: (a) AR Micrograph. Ferrite $(\alpha)$ and austenite $(\gamma)$. Beraha etching. (b) Micrograph SDSS: Aged $0.5 \mathrm{~h}$ at $800^{\circ} \mathrm{C}$. Showing ferrite $(\alpha)$, austenite $(\gamma)$ and $\sigma$. Beraha etching. (c) Micrograph SDSS: Aged $50 \mathrm{~h}$ at $750^{\circ} \mathrm{C}$. Showing austenite $(\gamma)$, sigma phase $(\sigma)$ and secondary austenite $\left(\gamma_{2}\right)$. Beraha etching. (d) Micrograph SDSS: Aged $50 \mathrm{~h}$ at $800^{\circ} \mathrm{C}$. Showing austenite $(\gamma)$ and sigma phase $(\sigma)$. Electrolytic etching

at the initial heat treatment times (about $7.5 \mathrm{~h}$ ) the ferrite transforms into sigma and further the remaining ferrite transforms into secondary austenite and sigma. Therefore the magnetic measurements confirmed that the ferrite disappeared for the longer heat treatment times, which is shown in Figures 1c and 1d. Analyzing Vickers hardness in the samples, as shown in Figure 2, it is noted that the hardness in earlier times at $700^{\circ} \mathrm{C}$ and $750^{\circ} \mathrm{C}$ are below the value of the $\mathrm{HV}$ in AR sample. This can be explained by the coarsening that occurs in austenite, where the average austenite spacing increased of $24 \mu \mathrm{m}$ (AR) to $44 \mu \mathrm{m}$ (aged $0.5 \mathrm{~h}$ at $\left.700^{\circ} \mathrm{C}\right)$ and $31 \mu \mathrm{m}\left(\right.$ aged $0.5 \mathrm{~h}$ at $\left.750^{\circ} \mathrm{C}\right)$ but the same was not seen in the sample aged at $800^{\circ} \mathrm{C}$. For illustration effect is shown the micrograph of the sample aged at $700^{\circ} \mathrm{C}$ for $0.5 \mathrm{~h}$, Figure 3 , where it is noted the thinning of ferrite in comparison to AR sample, shown in Figure 1a. This gives an indication of increased austenite spacing via thermal treatment in the first heat treatment times which caused a decrease in hardness, as shown in Figure 2. From the time of appearance and growth of sigma phase at temperatures of 700 and $750^{\circ} \mathrm{C}$, from $3.5 \mathrm{~h}$, hardness increases and follows

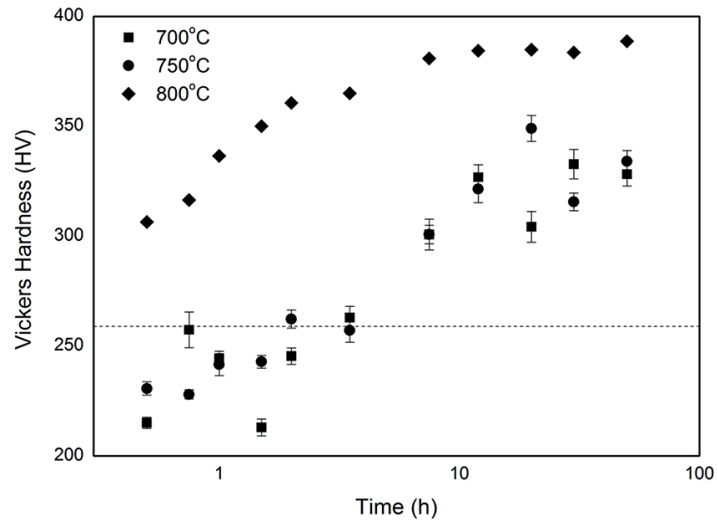

Figure 2: Vickers Hardness at $700^{\circ} \mathrm{C}, 750^{\circ} \mathrm{C}$ and $800^{\circ} \mathrm{C}$. The dashed line represents the hardness of the $\mathrm{AR}$ sample. The errors measured in the samples heat treated at $800^{\circ} \mathrm{C}$ are smaller than the symbol used in Figure and not are shown (used load 200 gram-force).

the trend of the samples heat treated at $800^{\circ} \mathrm{C}$. At $800^{\circ} \mathrm{C}$ like the sigma phase is formed and grows considerably after $0.5 \mathrm{~h}$, the hardness is already higher than AR sample and increases as a function of heat treatment time. 


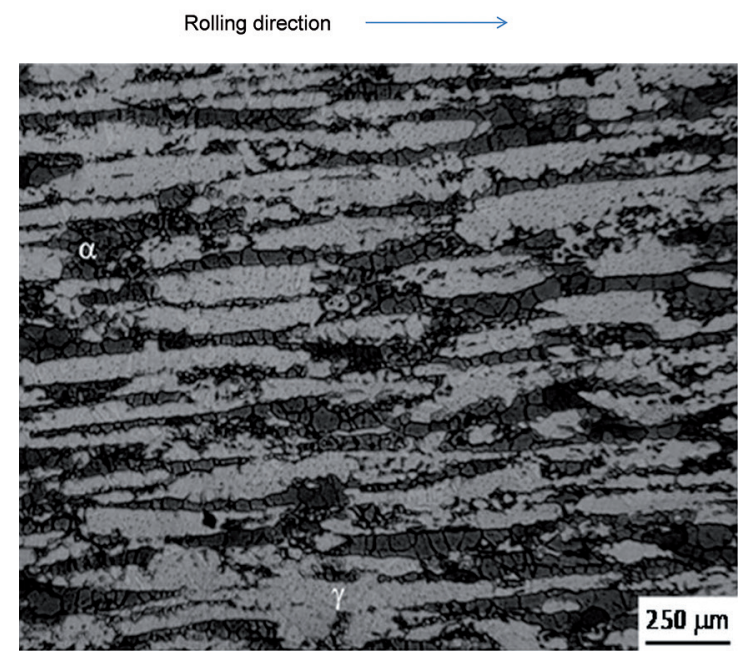

Figure 3: Micrograph SDSS: Aged $0.5 \mathrm{~h}$ at $700^{\circ} \mathrm{C}$. Showing thinning of ferrite in comparison to AR sample, shown in Figure 1a. Beraha etching.

The verification of the phases present was also performed via $\mathrm{XRD}$, and is shown in Figures 4,5 and 6 to $700^{\circ} \mathrm{C}, 750^{\circ} \mathrm{C}$ and $800^{\circ} \mathrm{C}$. The diffracted planes sigma phase are: (410); (420); (411) and (331) respectively. The XRD technique has the limitation of detecting small amounts in volume of phases. In this work the XRD technique detects the presence of sigma phase only after $7.5 \mathrm{~h}$ at $700^{\circ} \mathrm{C}$, unlike obtained via $\mathrm{OM}$, that $2 / 3.5 \mathrm{~h}$ at $700^{\circ} \mathrm{C}$ which it is possible to note the presence of sigma phase. But qualitatively via XRD, it can be observed a reduction peak ferrite and the appearance and increase of the peak of sigma phase in all diffractograms. It is interesting to note that with increasing temperature the peaks related to sigma phase appear more quickly. The initial heat treatment times, around $0.5 \mathrm{~h}$ at $800^{\circ} \mathrm{C}$, there is already a considerable amount of sigma phase formed, confirming that the kinetics of formation of this phase at $800^{\circ} \mathrm{C}$ is faster in comparison to $700^{\circ} \mathrm{C}$ and $750^{\circ} \mathrm{C}$.

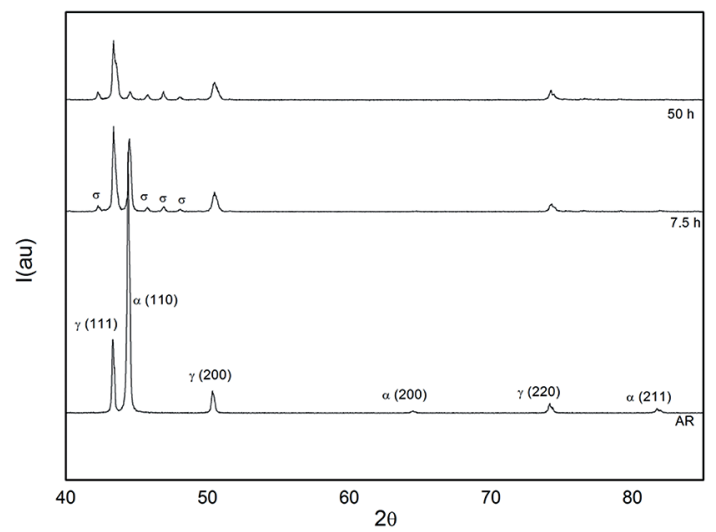

Figure 4: X-Ray diffraction patterns at $700^{\circ} \mathrm{C}$. AR, aged $7.5 \mathrm{~h}$ and $50 \mathrm{~h}$.

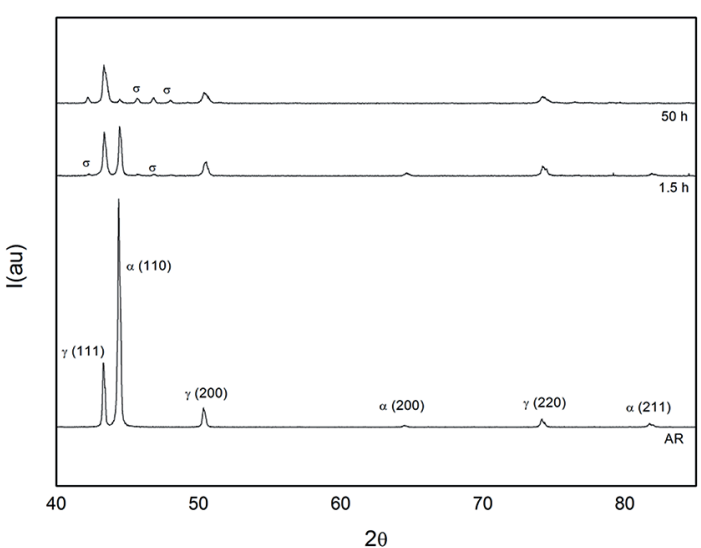

Figure 5: X-Ray diffraction patterns at $750^{\circ} \mathrm{C}$. AR, aged for $1.5 \mathrm{~h}$ and $50 \mathrm{~h}$.

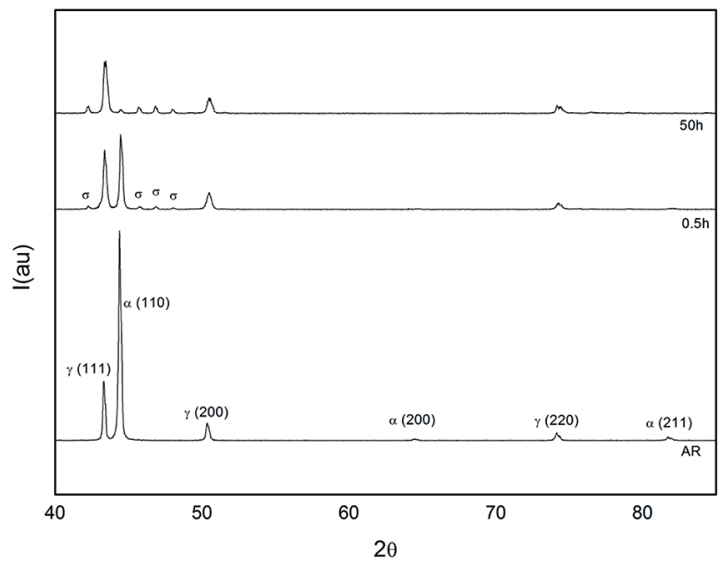

Figure 6: X-Ray diffraction patterns at $800^{\circ} \mathrm{C}$. AR, aged for $0.5 \mathrm{~h}$ and $50 \mathrm{~h}$.

The kinetics of transformation was studied by JMAK equations, and the microstructural partial path (MP) $S_{V}$ versus $V_{V}$ and $\left\langle\lambda>\right.$ versus $V_{V}$. Figures 7, 8 and 9 show $V_{V}$ as a function of time to $700^{\circ} \mathrm{C}, 750^{\circ} \mathrm{C}$ and $800^{\circ} \mathrm{C}$, respectively. The experimental data were fitted to Eq.1 together with Eq.2.

Analyzing Figures 7 to 9, it is clear change mechanism in the nucleation and growth of sigma phase. The mechanism 1 (interface controlled growth) is the equation JMAK combining Eq.1 and Eq. 2, with $\mathrm{n}$ approximately equal to 2.7, and activation energy, $\mathrm{Q}=421 \mathrm{~kJ} / \mathrm{mol}$ for all temperatures. Well the value of $n=2.7$ is very close to 3 , which indicates site saturation $^{24,25}$ and the process is controlled by the interface, which is also clear from the found value of Q $(421 \mathrm{~kJ} / \mathrm{mol})$ bigger than $\mathrm{Q}$ for Cr-diffusion in grain-boundary in $\alpha$-Fe $(218 \mathrm{~kJ} / \mathrm{mol})^{26}$ and $\mathrm{Q}$ for Mo diffusion in ferrite $(\cong 289 \mathrm{~kJ} /$ $\mathrm{mol})^{2,27}$. With $3.2 \mathrm{~h}$ at $700^{\circ} \mathrm{C}, 1.4 \mathrm{~h}$ at $750^{\circ} \mathrm{C}$ and $0.8 \mathrm{~h}$ at $800^{\circ} \mathrm{C}$, there is a change mechanism. The mechanism 2 (diffusion controlled growth). is the equation JMAK combining Eq. 1 


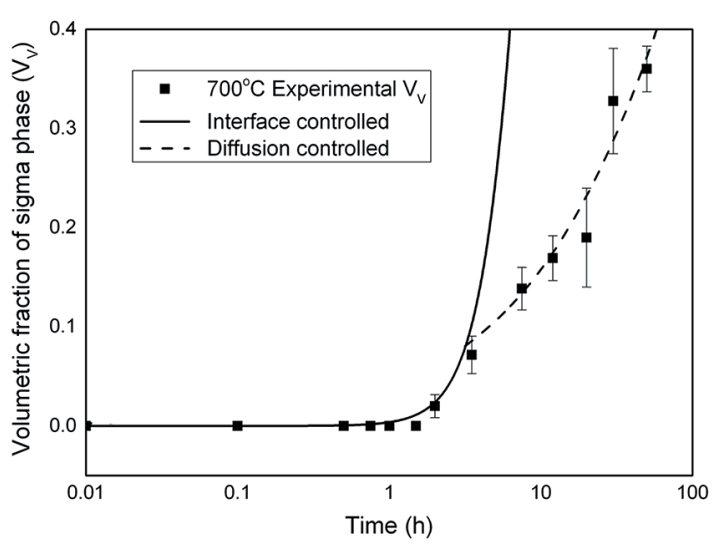

Figure 7: Volumetric fraction of sigma phase $\left(V_{V}\right)$ against time data of specimens aged at $700^{\circ} \mathrm{C}$. The solid line represents mechanism 1 (interface controlled growth) and dashed line represents mechanism 2 (diffusion controlled growth).

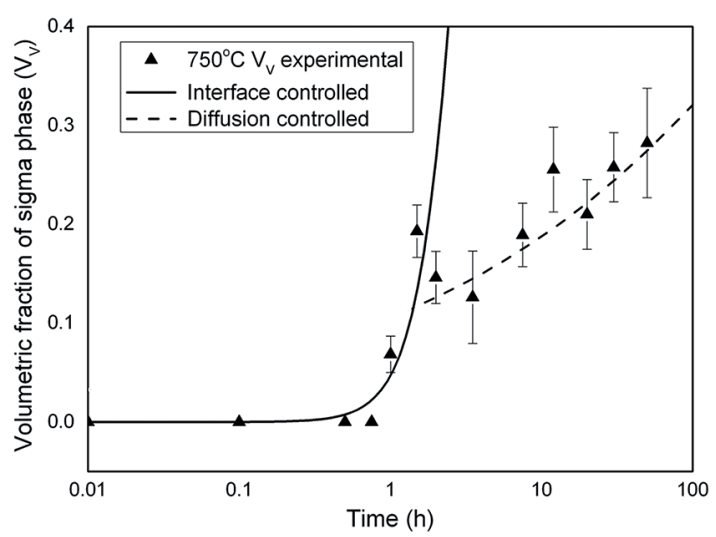

Figure 8: Volumetric fraction of sigma phase $\left(V_{V}\right)$ against time data of specimens aged at $750^{\circ} \mathrm{C}$. The solid line represents mechanism 1 (interface controlled growth) and dashed line represents mechanism 2 (diffusion controlled growth).

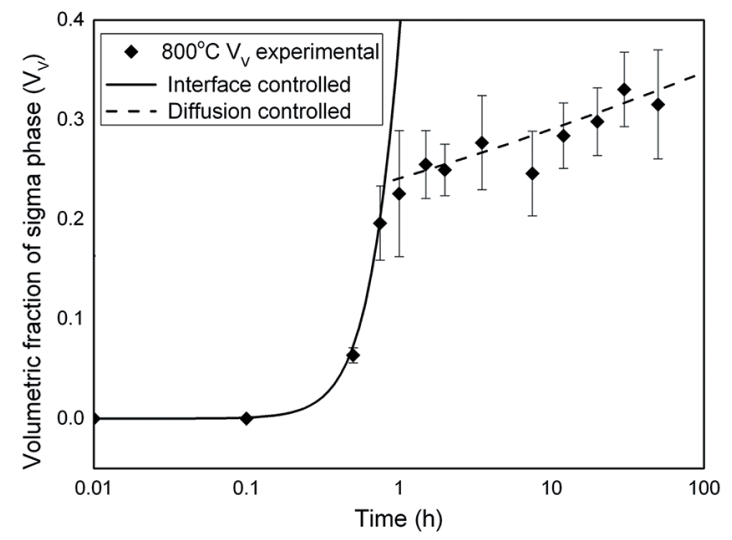

Figure 9: Volumetric fraction of sigma phase $\left(V_{V}\right)$ against time data of specimens aged at $800^{\circ} \mathrm{C}$. The solid line represents mechanism 1 (interface controlled growth) and dashed line represents mechanism 2 (diffusion controlled growth). and Eq. 2, with $\mathrm{n}<1$ and activation energy, $\mathrm{Q}=165 \mathrm{~kJ} / \mathrm{mol}$ for all temperatures. In this case, as the shift mechanism in the aforementioned times, indicate that the process, in the mechanism 2, is diffusion controlled, and in this case, most likely by diffusion of chromium. The slope change in JMAK curves has been found by other authors ${ }^{8}$. The main problem of analyzing by JMAK, about the nucleation mode, that is, only by $V_{V}$ in practice, as shown here are deviations of the assumptions from the model. Therefore, MP formulation by $S_{V}$ $\mathrm{e}<\lambda>$ helps to respond on the nucleation mode. The discussion addressed in the manuscript is focused on two theories: The JMAK and complementarily the microstructural path (MP). The MP formulation was applied to demonstrate the nucleation mode. Thus, by applying both theories we could discuss the kinetics and their nucleation in a complementary fashion. Indeed, the results showed dispersions for both mechanism, but the general trend is clear. This paper proposed to explain using two kinetics equations based on two nucleation control (interface controlled growth and diffusion controlled growth).

Figure 10 shows the data as $S_{V} /\left(1-V_{V}\right)$ versus $-\ln \left(1-V_{V}\right)$ for the studied temperatures. Two lines are plotted in each figure. One represents Eq. 3 with $q=0.667$, which means site-saturation with uniform impingement and other line represents Eq. 3 with $\mathrm{q}=0.5$, which means linear impingement. Indeed, examining Figure 10, it is seen that the data initially adjust the site saturation with impingement uniform but late times the change occurs for linear impingement, in accordance with shown in Figures 7 to 9, with difference in this case not only indicates a change in the mechanism, but indicates the location of impingement, which would be in the grain edges. Therefore sigma phase nucleates on edges. In this case, the edges of ferrite/austenite and ferrite/ferrite.

This result suggests that MP using $\langle\lambda>$, Eq.4, would give $p=1 / 6$. In order to test this suggestion, Figure 11 shows $<\lambda>/\left(\mathrm{V}_{\mathrm{v}}\right)^{1 / 3}$ versus $-\ln \left(1-\mathrm{V}_{\mathrm{v}}\right)$. Data are fitted with Eq. 4 considering linear impingement $(p=1 / 6)$ and uniform impingement $(p=0)$. Analysis of Figure 11 suggests a transition of random nucleation $(p=0)$ for the case of linear impingement $(p=1 / 6)$. Therefore, the microstructural path theory gave additional and more precise information to complete assessment of the sigma phase transformation on the SDSS used in these experiments.

\section{Conclusion}

The mechanism formation, kinetics and microstructural path of sigma phase in a UNS S32750 superduplex stainless steel were studied. Based on the results of samples undergoing isothermal aging at temperatures $700^{\circ} \mathrm{C}, 750^{\circ} \mathrm{C}$ and $800^{\circ} \mathrm{C}$, the main conclusions were:

- The sigma phase directly influences the hardness of the material. At $800^{\circ} \mathrm{C}$, aged for $0.5 \mathrm{~h}$, the hardness 


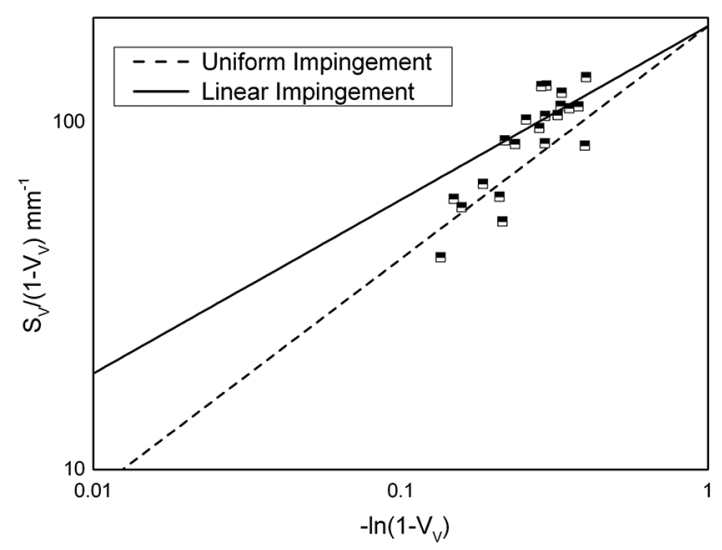

Figure 10: MP, $S_{V}$ in function of the $V_{V}$, with Uniform Impingement and Linear Impingement for SDSS undergoing aging in the temperature range $700^{\circ} \mathrm{C}-800^{\circ} \mathrm{C}$.

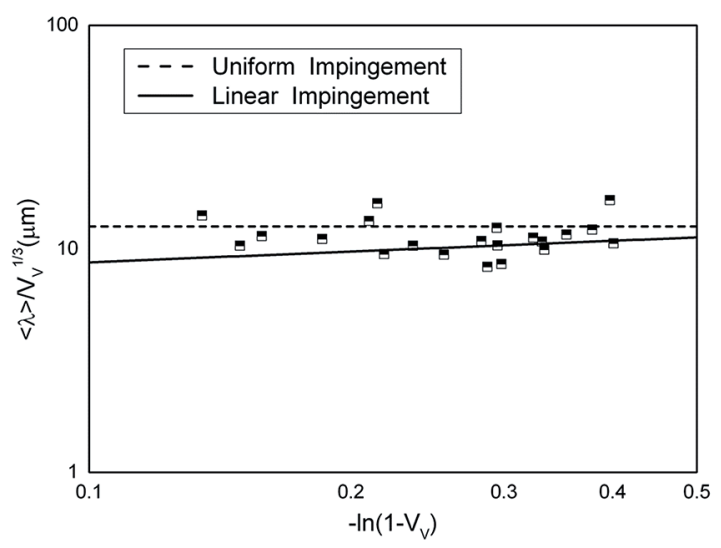

Figure 11: MP, $<\lambda>$ in function of the $V_{v}$, with Uniform Impingement and Linear Impingement for SDSS undergoing aging in the temperature range $700^{\circ} \mathrm{C}-800^{\circ} \mathrm{C}$.

was $18 \%$ higher than in the AR sample. At $700^{\circ} \mathrm{C}$ and $750^{\circ} \mathrm{C}$, in earlier times of heat treatment, the austenite grows, so the hardness decreases compared the AR sample. At $700^{\circ} \mathrm{C}$ and $750^{\circ} \mathrm{C}$, aged from $3.5 \mathrm{~h}$, the hardness increases with the increase of sigma phase and follows the trend of the samples aged at $800^{\circ} \mathrm{C}$.

- $\quad$ By applying the traditional JMAK equation, we can see a shift mechanism in the nucleation and growth of the sigma phase in temperatures studied. Site saturation occurs in the samples and initially control is by interface. With $3.2 \mathrm{~h}$ at $700^{\circ} \mathrm{C}, 1.4 \mathrm{~h}$ at $750^{\circ} \mathrm{C}$ and $0.8 \mathrm{~h}$ at $800^{\circ} \mathrm{C}$, the change occurs and control is by diffusion. Probably the diffusion of $\mathrm{Cr}$ in Ferrite.

- $\quad$ For the first time is applied the microstructural partial path, in study of sigma phase precipitation in superduplex stainless steel. And the method either by $S_{V}$ or $\langle\lambda>$ indicates that the nucleation is site- satured with anisotropic linear impingement. This means that sigma phase nucleates on edges. In this case, the edges of ferrite/austenite and ferrite/ferrite.

\section{Acknowledgments}

This work was supported by Conselho Nacional de Desenvolvimento Cientıfico e Tecnológico, CNPq, Coordenação de Aperfeiçoamento de Pessoal de Nível Superior, CAPES, and Fundação de Amparo a Pesquisa do Estado do Rio de Janeiro, FAPERJ.

\section{References}

1. Escriba DM, Materna-Morris E, Plaut RL, Padilha AF. Chi-phase precipitation in a duplex stainless steel. Materials Characterization. 2009;60(11):1214-1219. doi: 10.1016/j.matchar.2009.04.013

2. Magnabosco R. Kinetics of sigma phase formation in a Duplex Stainless Steel. Materials Research. 2009;12(3):321-327. http:// dx.doi.org/10.1590/S1516-14392009000300012

3. Calliari I, Zanesco M, Ramous E. Influence of isothermal aging on secondary phases precipitation and toughness of a duplex stainless steel SAF 2205. Journal of Materials Science. 2006;41(22):7643-7649. doi: 10.1007/s10853-006-0857-2

4. Dobranszky J, Szabo PJ, Berecz T, Hrotko V, Portko M. Energydispersive spectroscopy and electron backscatter diffraction analysis of isothermally aged SAF 2507 type superduplex stainless steel. Spectrochimica Acta Part B: Atomic Spectroscopy. 2004;59(10-11):1781-1788. doi: 10.1016/j.sab.2004.07.010

5. Hsieh CC, Wu W. Overview of Intermetallic Sigma $(\sigma)$ Phase Precipitation in Stainless Steels. International Scholarly Research Network Metallurgy. 2012;2012:732471. doi: $10.5402 / 2012 / 732471$

6. Kobayashi DY, Wolynec S. Evaluation of the low corrosion resistant phase formed during the sigma phase precipitation in duplex stainless steels. Materials Research. 1999;2(4):239-247. http://dx.doi.org/10.1590/S1516-14391999000400002

7. Villanueva DME, Junior FCP, Plaut RL, Padilha AF. Comparative study on sigma phase precipitation of three types of stainless steels: austenitic, superferritic and duplex. Materials Science and Technology. 2006;22(9):1098-1104. doi: 10.1179/174328406X109230

8. Elmer JW, Palmer TA, Specht ED. Direct Observations of Sigma Phase Formation in Duplex Stainless Steels Using In-Situ Synchrotron X-Ray Diffraction. Metallurgical and Materials Transactions A. 2007;38(3):464-475. doi: 10.1007/ s11661-006-9076-3

9. Badji R, Bouabdallah M, Bacroix B, Kahloun C, Belkessa B, Maza $\mathrm{H}$. Phase transformation and mechanical behavior in annealed 2205 duplex stainless steel welds. Materials Characterization. 2008;59(4):447-453. doi: 10.1016/j.matchar.2007.03.004

10. Fan K, Liu F, Ma YZ, Yang GC, Zhou YH. Modeling of $\sigma$-phase precipitation in a 2205 duplex stainless steel using an analytical soft impingement treatment. Materials Science and Engineering: A. 2010;527(18-19):4450-4553. doi: 10.1016/j. msea.2010.04.074 
11. Johnson WA, Mehl RF. Reaction kinetics in processes of nucleation and growth. Transactions of the American Institute of Mining and Metallurgical Engineers. 1939;135:416-441.

12. Avrami M. Kinetics of phase change. I General theory. The Journal of Chemical Physics. 1939;7(12):1103-1112. http:// dx.doi.org/10.1063/1.1750380

13. Avrami M. Kinetics of phase change. II Transformation-time relations for random distribution of nuclei. The Journal of Chemical Physics. 1940;8(2):212-224. http://dx.doi.org/10.1063/1.1750631

14. Avrami M. Granulation, phase change, and microstructure kinetics of phase change. III. The Journal of Chemical Physics. 1941;9(2):177-184. http://dx.doi.org/10.1063/1.1750872

15. Kolmogorov AN. The statistics of crystal growth in metals. Isvestiia Academii Nauk SSSR - Seriia Matematicheskaia. 1937;1:333-359.

16. Gokhale AM, Dehoff RT. Estimation of nucleation rate and growth rate from time dependence of global microstructural properties during phase transformations. Metallurgical Transactions A. 1985;16(4):559-564. doi: 10.1007/BF02814229

17. Vandermeer RA, Rath BB. Modeling recrystallization kinetics in a deformed iron single crystal. Metallurgical Transactions A. 1989;20(3):391-401. doi: 10.1007/BF02653918

18. Vandermeer RA, Masumura RA. The microstructural path of grain-boundary-nucleated phase transformations. Acta Metallurgica et Materialia. 1992;40(4):877-886. doi:10.1016/09567151(92)90031-9
19. Vandermeer RA, Jensen DJ. The Migration of High Angle Grain Boundaries During Recrystallization. Interface Science. 1998;6(1):95-104. doi: 10.1023/A:1008668604733

20. Vandermeer RA, Jensen DJ. Microstructural path and temperature dependence of recrystallization in commercial aluminum. Acta Materialia. 2001;49(11):2083-2094. doi: 10.1016/S1359-6454(01)00074-X

21. Vandermeer RA. Microstructural descriptors and the effects of nuclei clustering on recrystallization path kinetics. Acta Materialia. 2005;53(5):1449-1457. doi: 10.1016/j.actamat.2004.10.054

22. Sieurin H, Sandström R. Sigma phase precipitation in duplex stainless steel 2205. Materials Science and Engineering: A 2007;444(1-2):271-276. doi: 10.1016/j.msea.2006.08.107

23. Russ JC, Dehoff RT. Practical stereology. $2^{\text {nd }}$ ed. New York: Kluwer Academic/Plenum Publishers; 2000. p. 45-78.

24. Christian JW. The theory of transformations in metals and alloys: Part I. $3^{\text {rd }}$ ed. Oxford: Elsevier; 2002.

25. Rios PR, Padilha AF. Microstructural path of recrystallization in a commercial Al-Mn-Fe-Si (AA3003) alloy. Materials Research.2003;6(4):605-613. http://dx.doi.org/10.1590/S151614392003000400030

26. Wang ZB, Tao NR, Tong WP, Lu J, Lu K. Diffusion of chromium in nanocrystalline iron produced by means of surface mechanical attrition treatment. Acta Materialia. 2003;51(14):4319-4329. doi: 10.1016/S1359-6454(03)00260-X

27. Nitta H, Miura K, Iijima Y. Self-diffusion in iron-based Fe-Mo alloys. Acta Materialia. 2006;54(10):2833-2847. doi: 10.1016/j. actamat.2006.02.020 